\title{
Changes in body temperature and circulating levels of interleukin-6 after intra-arterial injections or infusions of tumor necrosis factor $\alpha$ in guinea pigs
}

\author{
J. Roth, J. L. McClellan ${ }^{\mathrm{a}}$, M. J. Kluger ${ }^{\mathrm{a}}$ and E. Zeisberger \\ Physiologisches Institut, Klinikum der Jusius-Liebig-Universität, Aulweg 129, D-35392 Giessen (Germany) and \\ ${ }^{a}$ University of Michigan-Medical School, Department of Physiology, Ann Arbor (Michigan 48109, USA) \\ Received 5 April 1994; accepted 8 June 1994
}

\begin{abstract}
Tumor necrosis factor $\alpha$ (TNF) is released systematically during the early phase of endotoxin induced fever ${ }^{l}$. To study the effects of this cytokine in guinea pigs, $2 \mu \mathrm{g}$ TNF were intra-arterially injected as a bolus or slowly infused within $60 \mathrm{~min}$. Both modes of administration induced a biphasic elevation of the animals' abdominal temperature lasting $6 \mathrm{~h}$ and stimulated the release of endogenous interleukin-6 (IL-6)-like activity. The second phase of the thermal response and the release of endogenous IL-6-like activity were significantly higher, when TNF was slowly infused into the animals' circulation, in spite of a transiently higher TNF-like activity after the bolus injection of TNF. Both TNF and IL-6 may therefore be regarded as candidates to trigger the febrile response in guinea pigs.
\end{abstract}

Key words. Cytokines; tumor necrosis factor $\alpha$; interleukin-6; body temperature; fever; radiotelemetry; guinea pig.

Injection of man or experimental animals with lipopolysaccharide (LPS), a constituent of the gram-negative bacterial cell wall, causes fever by stimulating cells of the immune system to release cytokines, called endogenous pyrogens. Circulating tumor necrosis factor $\alpha$ (TNF) and interleukin-6 (IL-6) associated with those cytokines that can be measured in increased amounts after administration of LPS'. Both of these cytokines are released into the systemic circulation with very characteristic kinetics as determined in rats $^{2,3}$, baboons $\mathrm{s}^{4,5}$ and guinea pigs ${ }^{6}$. In these species TNF shows a transient appearance with a brief, early peak measurable of about $1 \mathrm{~h}$ after administration of LPS followed by a rapid decline and disappearance from the circulation. Systemic levels of IL-6 rise to a later peak parallel to the febrile changes of body temperature evoked by LPS application. Because of these patterns of release of cytokines after induction of endotoxemia, TNF has been proposed to be one of the initial mediators in the cytokine cascade ${ }^{7,8}$. The role of TNF in LPS-induced fever is, however, not clear and has aroused controversy (ref. 1, for review). For example, injection of rabbits with small amounts of TNF $(1 \mu \mathrm{g} / \mathrm{kg})$ caused a rather short monophasic fever; larger amounts of TNF $(10 \mu \mathrm{g} /$ $\mathrm{kg}$ ) evoked a much longer biphasic elevation of body temperature ${ }^{9}$. The authors of that study attributed the second peak of the bimodal febrile response to IL-1-like activity induced by TNF. It was, however, not shown whether the amounts of TNF, which caused fever and release of IL-1 in rabbits, corresponded to the levels of TNF detected during LPS induced fever. Circulating levels of TNF during endotoxemia or TNF infusion and corresponding febrile and metabolic responses were studied in cancer patients ${ }^{10}$ and were found to be com- parable under both conditions. However, injection of rats with doses of TNF ranging from $1-50 \mu \mathrm{g} / \mathrm{kg}$ did not result in febrile body temperature changes, and fevers induced by LPS or IL- $1 \beta$ were even attenuated by additional injections of $\mathrm{TNF}^{11}$. Injection of rats with TNF-antiserum, which was able to neutralize TNF-like bioactivity in rats, $2 \mathrm{~h}$ prior to injection of LPS, attenuated the short initial phase of the febrile response but significantly enhanced the longer second phase of the bimodal fever ${ }^{3}$. These data suggested that TNF may be involved in the initiation of the first phase of fever, but might then provide a signal for a limitation of the second phase of the febrile response and thus act as an endogenous antipyretic.

In two previous studies ${ }^{6,12}$, we determined bioactivity of TNF during LPS induced fevers in guinea pigs based on the cytotoxic effect of this cytokine on the mouse fibrosarcoma cell line WEHI 164 subclone $13^{13}$. In these studies peak activity of TNF in blood plasma was measured $60 \mathrm{~min}$ after injection of LPS with mean values of 680 units $/ \mathrm{ml}^{6}$ and 505 units $/ \mathrm{ml}^{12}$, respectively. In the present investigation we used a human recombinant (hr) TNF preparation with a specific activity of 20,000 units $/ \mu \mathrm{g}$, also determined by the WEHI bioassay, and tried to simulate the peak activity of TNF during LPS fever in guinea pigs by intra-arterial injections or infusions. The effects of these TNF administrations on abdominal temperature and systemic IL-6-like activity were recorded in our experiments.

\section{Materials and methods}

Animals. This study was performed in 16 male guinea pigs with a mean body weight of $465 \pm 12 \mathrm{~g}$ at the 
beginning of the experiments. The animals were housed in individual cages at $22{ }^{\circ} \mathrm{C}$ with a $12: 12 \mathrm{~h}$ light-dark cycle (light off at $19.00 \mathrm{~h}$ ).

Surgery and sampling of blood plasma. At least one week before the start of the experimental procedure, the animals were chronically implanted with intra-arterial catheters. Guinea pigs were anesthetized with $100 \mathrm{mg} /$ $\mathrm{kg}$ ketamine hydrochloride and $4 \mathrm{mg} / \mathrm{kg}$ xylazin. Polyethylene catheters were inserted through the left carotid artery until reaching the aortic arch. The distal ends of the catheters were tunnelled subcutaneously to the interscapular region of the back where they emerged through the skin according to the method described by Shrader and Everson ${ }^{14}$. After implantation, the catheters were flushed with sterile heparinized saline and closed by heating. During the experiments single arterial blood samples $(0.5 \mathrm{ml})$ were slowly (within $1 \mathrm{~min}$ ) drawn into sterile syringes, put into chilled polypropylene tubes and immediately centrifuged. The blood plasma was stored at $-70^{\circ} \mathrm{C}$ for later determination of cytokines. Before the experiments, the animals were accustomed to the blood sampling procedure, which did not cause excitement or any measurable change in body temperature.

Measurement of body temperature. Abdominal temperature was measured by use of battery operated biotelemetry transmitters (VM-FH-discs, Mini-Mitter Co., Sunriver, Oregon, USA) implanted i.p. after placement of the intra-arterial catheter. Output (frequency in $\mathrm{Hz}$ ) was monitored by a mounted antenna placed under each animal's cage (RA 1000 radioreceivers, Mini-Mitter Co., Sun River, Oregon, USA) and multiplexed by means of a BCM 100 consolidation matrix to an IBM personal computer system. A Dataquest IV data acquisition system (Data Sciences Inc., St. Paul, Minnesota, USA) was used for automatic control of data collection and analysis. Abdominal temperature, which was taken as an index of core temperature, was monitored and recorded at $5 \mathrm{~min}$ intervals.

Experimental procedure. In a first series of experiments 8 guinea pigs were intra-arterially injected with $2 \mu \mathrm{g} \mathrm{hr}$ TNF dissolved in $0.5 \mathrm{ml}$ sterile pyrogen free saline (specific activity 20,000 units/ $\mu \mathrm{g} ; \mathrm{Fa}$. Biermann $\mathrm{GmbH}$, Bad Nauheim, Germany) or with a corresponding volume of solvent alone. These two injections were performed 8 and 16 days after implantation of catheters and biotelemetry transmitters. Half of the animals were first injected with TNF, the other half with solvent, and 8 days later vice versa. After the injection the catheters were flushed with saline. Blood plasma samples were collected in 6 animals $60 \mathrm{~min}$ prior to TNF injection as well as $1 \mathrm{~min}, 60 \mathrm{~min}$ and $180 \mathrm{~min}$ after TNF injection, and assayed for TNF-like and IL-6-like activities.

In a second series of experiments another group of 8 guinea pigs were infused i.a. with $2 \mu \mathrm{g}$ of the same TNF preparation (see above) dissolved in $2 \mathrm{ml}$ sterile pyrogen free saline or with a corresponding volume of solvent alone. The distal end of the catheter was connected by polyethylene tubing to a $5 \mathrm{ml}$ glass syringe fixed to an infusion pump (Fa. Braun, Melsungen, Germany). The infusions lasted $60 \mathrm{~min}$ and were performed 8 days and 16 days after implantation of catheters and biotelemetry transmitters. Half of the animals were first infused with TNF, the other half with solvent, and 8 days later vice versa. At the end of the infusion and prior to samplings of blood, the catheters were flushed with saline. Blood plasma samples were collected in 6 animals 60 min prior to the start of TNF infusion as well as $15 \mathrm{~min}, 60 \mathrm{~min}$, $180 \mathrm{~min}$ and $360 \mathrm{~min}$ after the start of TNF infusion, assayed for TNF-like and Il-6-like activities.

Bioassay for TNF. Determination of TNF was based on the cytotoxic effect of this cytokine on the mouse fibrosarcoma cell line WEHI 164 subclone $13^{13}$. The cells were kindly provided by Dr. A. Waage (University of Trondheim, Norway). Plasma samples to be tested for TNF were serially diluted in assay medium consisting of $1 \%$ fetal calf serum, $2 \mathrm{mM} \mathrm{L}$-glutamine, $100 \mathrm{U} / \mathrm{ml}$ penicillin and $100 \mu \mathrm{g} / \mathrm{ml}$ streptomycin in RPMI 1640 (GIBCO, Long Island, NY, USA), and $100 \mu \mathrm{l}$ volumes were added in triplicate to 96-well tissue culture plates. The first sample was 1:10 diluted plasma, which was further serially diluted in assay medium $1: 20,1: 40$, $1: 80,1: 160,1: 320,1: 640,1: 1280$ and $1: 2560$. By this wide range of dilutions it was guaranteed that each sample was diluted below the detection limit of the assay. Cells were washed, resuspended at 500,000 cells/ $\mathrm{ml}$ in growth medium consisting of $10 \%$ fetal calf serum, $2 \mathrm{mM} \mathrm{L-glutamine,} 100 \mathrm{U} / \mathrm{ml}$ penicillin and $100 \mu \mathrm{g} / \mathrm{ml}$ streptomycin in RPMI 1640 , supplemented with $10 \mathrm{U} / \mathrm{ml}$ sterile heparin and $0.5 \mu \mathrm{g} / \mathrm{ml}$ actinomycin D for the assay. $100 \mu \mathrm{l}$ of cell suspension ( 50,000 cells) was added to each well. The plates were incubated for $20 \mathrm{~h}$ at $37^{\circ} \mathrm{C}$, room air with $5 \% \mathrm{CO}_{2}$, and $98 \%$ humidity. Then $20 \mu \mathrm{l}$ of 3-(4,5-dimethylthiazol-2-yl)-2,5diphenyl-tetrazolium bromide (MTT, $5 \mathrm{mg} / \mathrm{ml}$, Sigma Co., St. Louis, Missouri, USA) was added to each well to determine the number of living cells (cytotoxicity). MTT is a tetrazolium salt that will form dark crystals when combined with metabolizing cells. After incubation for additional $4 \mathrm{~h}, 150 \mu \mathrm{l}$ of supernatant was removed from each well and $100 \mu l$ of isopropanol/ $0.04 \mathrm{~m}$ $\mathrm{HCl}$ was added. The plates were then wrapped in aluminium foil to protect them from light and left at room temperature for another $20 \mathrm{~h}$. Then the plates were read at $570 \mathrm{~nm}$ and $630 \mathrm{~nm}$ (for reference) using an EL 312 Bio-Kinetics reader (BIO-TEK Instruments Inc., Winooski, Vermont, USA). The units of TNF were calculated based on a purified recombinant human ( $\mathrm{rh}$ ) TNF standard run in the same assay with a specific activity of $1 \mathrm{U} / 0.037 \mathrm{ng}$ in the WEHI assay (Cetus, Emeryville, California, USA). $100 \mu \mathrm{l}$ of assay medium (see above) containing TNF with activities of $1,0.5,0.1$, 
$0.05, \quad 0.01,0.005,0.001,0.0005,0.0001,0.00005$, $0.00001,0.000005$ and 0.000001 units $/ \mu 1$ were used to produce a standard curve. From this standard curve, a best-fit line was used to calculate TNF activity in the plasma samples. We considered any value greater than two standard deviations above media containing no TNF to be the limit of sensitivity of the assay. For TNF this value approximated $1 \mathrm{U} / \mathrm{ml}$ (ref. 3 for further details). Since we did not neutralize the measured TNF activity in plasma samples, we refer to this activity throughout the manuscript as TNF-like activity.

Bioassay for IL-6. Determination of IL-6 was based on the dose-dependent growth stimulation of IL- 6 on the B 9 cell line, an IL-6 dependent mouse B-cell hybridoma $^{15}$. The B 9 cells were kindly provided by Dr. L. Aarden (University of Amsterdam, Netherlands). Plasma samples to be tested for IL-6 were serially diluted in $10 \%$ fetal calf serum, $2 \mathrm{mM}$ L-glutamine, $100 \mathrm{U} / \mathrm{ml}$ penicillin, and $10 \mu \mathrm{g} / \mathrm{ml}$ streptomycin in Iscove's modified Dulbecco's medium (Sigma Chemical Company, St. Louis, Missouri, USA) and $100 \mu 1$ volumes were added in triplicate to 96-well tissue culture plate. The first sample was 1:10 diluted plasma, which was further diluted in assay medium $1: 20,1: 50,1: 250$, $1: 1250,1: 6250,1: 31250$ and $1: 56250$. Cells were washed, resuspended at 50,000 cells $/ \mathrm{ml}$ in growth medium supplemented with $10 \mathrm{U} / \mathrm{ml}$ sterile heparin, and $100 \mu \mathrm{l}$ of cell suspension (5,000 cells) was added to each well. The plates were incubated for $72 \mathrm{~h}$ at $37^{\circ} \mathrm{C}$, room air with $5 \% \mathrm{CO}_{2}$, and $98 \%$ humidity. Then $20 \mu 1$ of MTT (see above) was added to each well to determine the number of living cells (cell proliferation). After incubation for additional $4 \mathrm{~h}, 150 \mu \mathrm{l}$ of supernatant was removed and $100 \mu \mathrm{l}$ of isopropanol/0.04 $\mathrm{m} \mathrm{HCl}$ was added to each well. The plates were protected from light and left at room temperature for another $20 \mathrm{~h}$ before being read at $570 \mathrm{~nm}$ and $630 \mathrm{~nm}$ (for reference) using an EL 312 Bio-kinetics reader (BIO-TEK Instruments Inc., Winooski, Vermont, USA). Units were then calculated based on a purified rh IL- 6 standard run in the same assay with a specific activity of $10^{9} \mathrm{U} / \mathrm{mg}$ in the B 9 assay (Dr. G. Wong, Ginetics Institute, University of Los Angeles, California, USA). $100 \mu \mathrm{l}$ of assay medium (see above) containing IL-6 with activities of $20,10,5,2.5,1.25,0.625,0.3125$, and 0.156 units/ $\mu l$ were used to produce a standard curve. From this standard curve, a best-fit line was used to calculate the IL- 6 activity in the samples. One unit is defined as the amount of IL- 6 found to cause half-maximal cell proliferation in the assay (ref. 2 for further details). Since we did not neutralize the measured IL- 6 activity in plasma samples, we refer to this activity throughout the manuscript as IL-6 like activity.

Evaluation and statistics. In graphs of the thermal responses to the injections or infusions of TNF and solvent abdominal temperature was plotted over time in 15 min intervals. Values were expressed as means \pm SEM. Thermal responses were compared by a one-factor analysis of variance (ANOVA) followed by Scheffe's post-hoc test. IL-6 activities were compared by t-tests or $t$-tests for paired observations when appropriate.

\section{Results}

Figure 1 summarizes the thermal response of guinea pigs to an intra-arterial bolus injection of $2 \mu \mathrm{g}$ hr TNF or solvent.

Administration of TNF evoked a biphasic elevation of abdominal temperature lasting together about $6 \mathrm{~h}$, the shorter first phase lasting just about $90 \mathrm{~min}$. Injection of saline did not alter the animals' body temperature apparently. The effects of intra-arterial injections of $2 \mu \mathrm{g}$ hr TNF on circulating levels of TNF-like and IL-6-like activities are summarized in figure 2.

Sixty minutes prior to administration of TNF, no TNFlike activity was measurable in blood plasma of guinea pigs. One minute after an intra-arterial bolus injection of $2 \mu \mathrm{g} \mathrm{hr}$ TNF with a specific activity of 20,000 units/ $\mu \mathrm{g}$, a circulating TNF-like activity of $2976 \pm 788$ units/ $\mathrm{ml}$ was detected. Sixty minutes after injection this value declined to $255 \pm 122$ units $/ \mathrm{ml}$ and $2 \mathrm{~h}$ later to $43 \pm 15$ units/ml. TNF-like activity could not be detected at any stage of the experiment if solvent was injected into the animals' circulation. At corresponding stages of the experiment, IL-6-like activity was $215 \pm 31$ units/ml $60 \mathrm{~min}$ prior to injection of TNF, $199 \pm 45$ units $/ \mathrm{ml}$ $1 \mathrm{~min}$ after injection, $946 \pm 147$ units $/ \mathrm{ml} 60 \mathrm{~min}$ after injection and $959 \pm 175$ units/ml $180 \mathrm{~min}$ after injection of TNF. IL-6-like activities measured $60 \mathrm{~min}$ and 180 min after administration of TNF were significantly higher than baseline activity measured $60 \mathrm{~min}$ prior to the injection $(p<0.01$ in both cases). In animals injected with solvent, no apparent changes of IL-6-like activity in comparison to the baseline values were observed $(158 \pm 97$ units $/ \mathrm{ml}$ measured $60 \mathrm{~min}$ after injection, $\mathrm{N}=4 ; 229 \pm 133$ units $/ \mathrm{ml}$ measured $180 \mathrm{~min}$ after

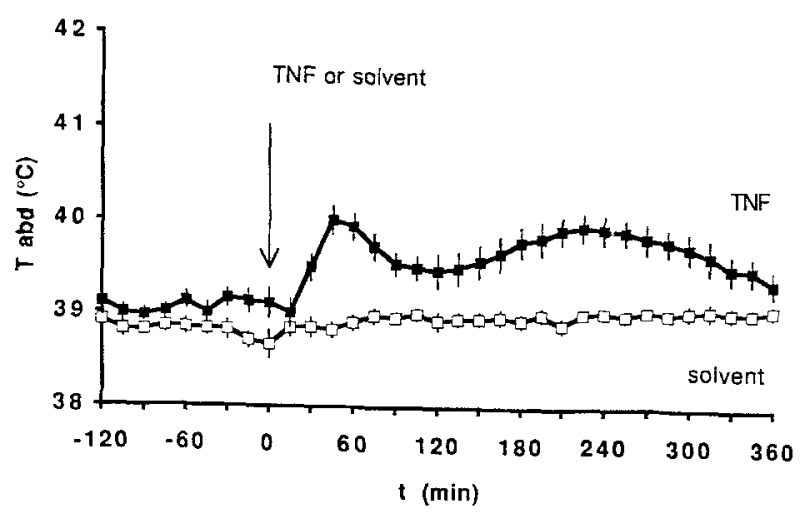

Figure 1. Thermal responses of guinea pigs $(N=8)$ to i.a. bolus injections of $2 \mu \mathrm{g} \mathrm{hr}$ TNF (black symbols) or solvent (open symbols). Abdominal temperatures are expressed as means, bars
indicate SEM. 

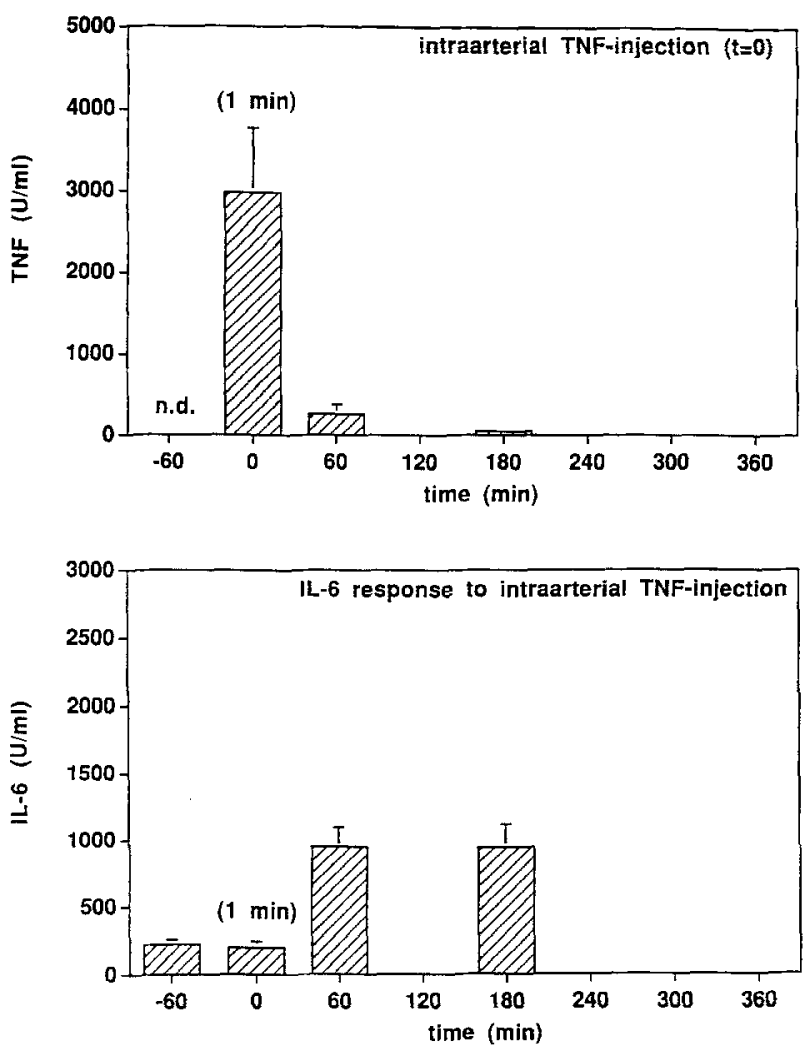

Figure 2. Upper part. TNF-like activity in arterial plasma of guinea pigs measured $60 \mathrm{~min}$ before; and $1 \mathrm{~min}, 60 \mathrm{~min}$ and $180 \mathrm{~min}$ after i.a. bolus injections of $2 \mu \mathrm{g} \mathrm{hr}$ TNF. Columns represent means of 6 animals, bars indicate SEM (n.d. = not detectable).

Lower part. IL-6-like activity in arterial plasma of guinea pigs measured $60 \mathrm{~min}$ before, and $1 \mathrm{~min}, 60 \mathrm{~min}$ and $180 \mathrm{~min}$ after i.a. bolus-injections of $2 \mu \mathrm{g} \mathrm{hr}$ TNF. Columns represent means of 6 animals, bars indicate SEM.

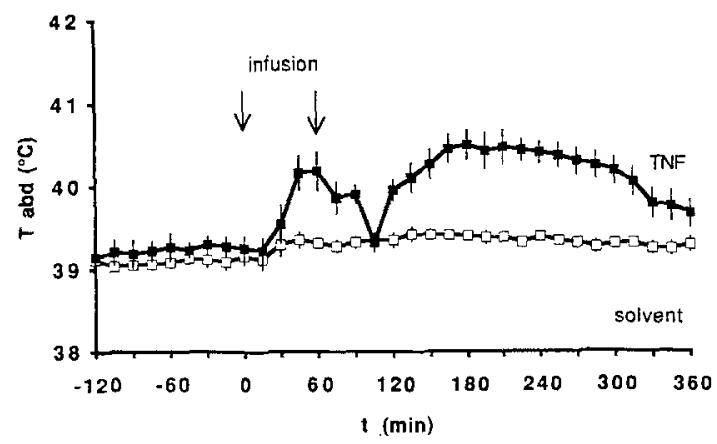

Figure 3. Thermal responses of guinea pigs $(N=8)$ to i.a. infusions of $2 \mu \mathrm{g} \mathrm{hr}$ TNF (black symbols) or solvent (open symbols) lasting $60 \mathrm{~min}$, as indicated by arrows. Abdominal temperatures are expressed as means, bars indicate SEM.

injection, $N=4$ ). Since the highest systemic levels of TNF-like activity during LPS fever in guinea pigs can be observed 60 min after injection of LPS, we administered $2 \mu \mathrm{g} \mathrm{hr}$ TNF in the second experiment not as a bolus injection but as an i.a. infusion lasting about $60 \mathrm{~min}$. The influence of i.a. infusions of TNF or solvent on body temperature are shown on figure 3 .
Intra-arterial infusions of $2 \mu \mathrm{g} \mathrm{hr}$ TNF evoked a similar biphasic elevation of body temperature as observed after TNF injection. Infusion of solvent caused just a slight increase of abdominal temperature. Between $120 \mathrm{~min}$ and $300 \mathrm{~min}$ after the start of TNF infusion the increase in abdominal temperature was significantly higher than at the corresponding time intervals after bolus injection of TNF ( $p<0.001$, ANOVA). Levels of TNF-like and IL-6-like activities at selected stages of the experiment are summarized in figure 4.

Fifteen minutes after the start of TNF infusion, TNFlike activity rose from an undetectable value measured $60 \mathrm{~min}$ prior to the infusion to a value of $339 \pm 61$ units/ $\mathrm{ml}$. This value further increased to $438 \pm 83$ units $/ \mathrm{ml}$ measured at the end of i.a. infusion with TNF. Two hours later TNF-like activity declined to $56 \pm 7$ units/ $\mathrm{ml}, 360 \mathrm{~min}$ after start of TNF infusion just $10 \pm 2$ units/ml of TNF-like activity were measured. TNF-like activity could not be detected at any stage of the experiment if solvent was infused into the animals' circulation. When $2 \mu \mathrm{g} \mathrm{hr}$ TNF was infused within $60 \mathrm{~min}$, a much stronger circulating IL-6-like activity was induced than observed after TNF injection. The baseline level of IL-6-like activity measured $60 \mathrm{~min}$ prior to the start of
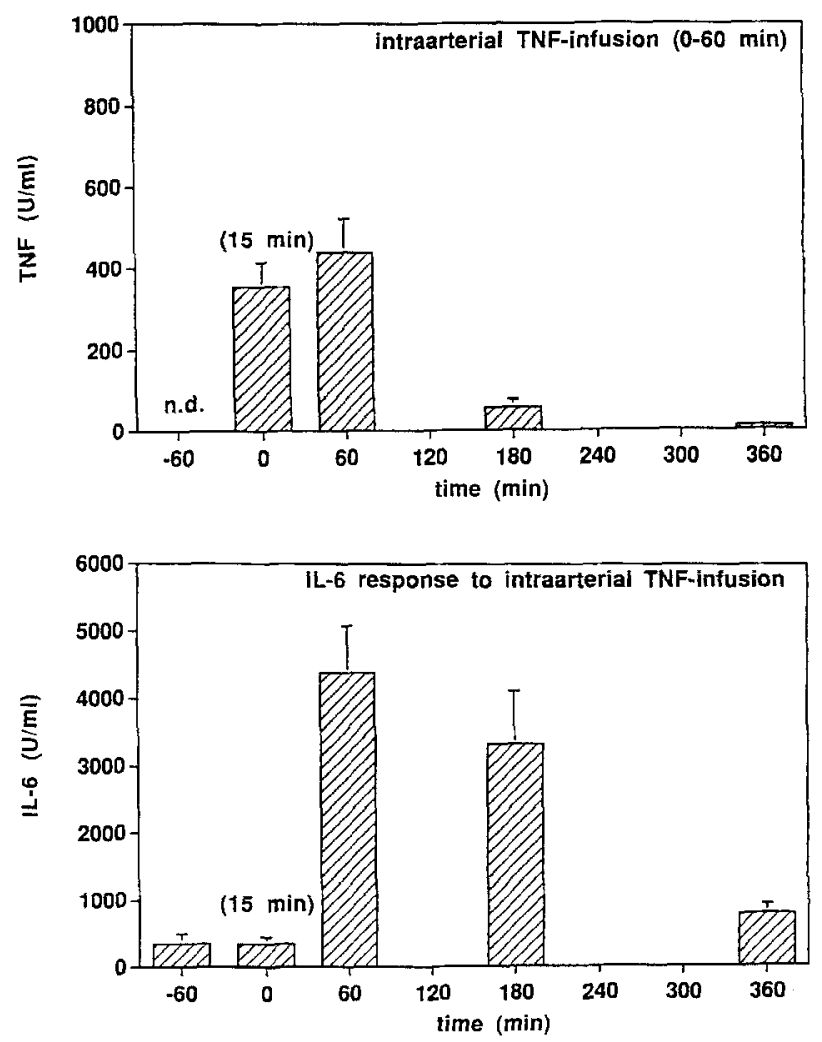

Figure 4. Upper part. TNF-like activity in arterial plasma of guinea pigs measured $60 \mathrm{~min}$ before, and $15 \mathrm{~min}, 60 \mathrm{~min}, 180 \mathrm{~min}$ and $360 \mathrm{~min}$ after the start of i.a. infusions of $2 \mu \mathrm{g} \mathrm{hr}$ TNF lasting $60 \mathrm{~min}$ (nd. = not detectable).

Lower part. IL-6-like activity in arterial plasma of guinea pigs measured $60 \mathrm{~min}$ before, and $15 \mathrm{~min}, 60 \mathrm{~min}, 180 \mathrm{~min}$ and $360 \mathrm{~min}$ after the start of i.a. infusions of $2 \mu \mathrm{g} \mathrm{hr} \mathrm{T} \cdot \mathrm{VF}$ lasting $60 \mathrm{~min}$. 
TNF infusion was $305 \pm 101$ units/ml. This value was not yet altered $15 \mathrm{~min}$ after the start of TNF infusion $(291 \pm 82$ units $/ \mathrm{ml})$. From this time until the end of the infusion, however, however, IL-6-like activity rose to $4382 \pm 696$ units.ml. Two hours later $3321 \pm 792$ units/ $\mathrm{ml}$ of IL-6-like activity were measured in arterial plasma. Six hours after the start of TNF infusion, almost at the end of the increased thermal response, IL-6-like activity in plasma declined again to $774 \pm 143$ units $/ \mathrm{ml}$. The circulating levels of IL-6-like activity measured $60 \mathrm{~min}$ and $180 \mathrm{~min}$ after the start of TNF infusion were significantly higher than the baseline value $(\mathrm{p}<0.001)$. Sixty minutes $(\mathrm{p}<0.001)$ and $180 \mathrm{~min}$ $(\mathrm{p}<0.01)$ after start of TNF infusion, IL-6-like activities were significantly higher than $60 \mathrm{~min}$ and $180 \mathrm{~min}$ after TNF injection. In animals infused with solvent, no apparent changes of IL-6-like activity in comparison to the baseline values were observed $(268 \pm 147$ units $/ \mathrm{ml}$ measured $60 \mathrm{~min}$ after start of the infusion, $\mathrm{N}=4$; $321 \pm 178$ units $/ \mathrm{ml}$ measured $60 \mathrm{~min}$ after start of the infusion, $\mathrm{N}=4 ; 392 \pm 196$ units $/ \mathrm{ml}$ measured $360 \mathrm{~min}$ after start of the infusion, $\mathrm{N}=3$ ).

\section{Discussion}

The original interest in TNF mainly arose from its selective toxic action on malignant cells. But later on much experimental evidence accumulated for the involvement of TNF in inflammation, cachexia, autoimmunity, infectious diseases and septic shock ${ }^{7}$. Bacterial LPS, which causes fever and can lead to septic shock at high doses, is a major inducer of TNF and other immune mediators called together the cytokine cascade ${ }^{8}$. TNF has been shown to induce fever after systemic administration. There is, however, only one study providing experimental evidence that the physiological dose of TNF, which transiently appears in the systemic circulation during the initial phase of LPS fever, is able to induce a febrile response ${ }^{10}$. In the present study we tried to inject or infuse amounts of bioactive TNF, which correspond to those observed during LPS fever, in guinea pigs ${ }^{6,12}$. Especially in the second experiment of this study, when we infused 40,000 units of TNF within $60 \mathrm{~min}$, TNF-like bioactivity in plasma was measured (438 units $/ \mathrm{mI}$ ) which was not higher than systemic activity of TNF in guinea pigs after i.m. injection of LPS (see introduction). The bioactivity of the TNF preparation that we used in the present study was tested by the same bioassay (WEHI 164 clone 13) which we applied for analysis of plasma samples of guinea pigs during LPS fever in previous studies ${ }^{6,12}$. Assuming that guinea pig TNF-like activity and human recombinant TNF have an equimolar bioactivity in the WEHI assay, a physiological amount of hr TNF was able to induce a biphasic elevation of body temperature and a significant increase in systemic IL-6-like activity. IL-6 is a cy- tokine, which is able to induce fever and synthesis of acute-phase proteins ${ }^{16,17}$ and which has been reported to be induced by $\mathrm{TNF}^{18}$. Therefore, it is not possible to decide whether the thermal response to administration of TNF was induced by TNF itself, by IL- 6 or by any other factor induced by TNF or IL-6. Interestingly, bolus-injections of $2 \mu \mathrm{g} \mathrm{hr}$ TNF evoked a smaller second fever phase and release of less IL-6-like activity than a slow infusion of the same amount of TNF, although transiently a higher systemic TNF-like activity could be observed after the bolus injection. Obviously this phenomenon was due to a more rapid inactivation of TNF after the bolus injection, while the infusions kept TNF-like activity at a constant level for about 60 min. Of course, our limited number of samples due to the small total blood volume of our experimental animal does not allow a description of a complete kinetics of injected or infused TNF, but protective inactivating mechanisms against high circulating levels of TNF have been described recently. Thus, in studies in man it could be demonstrated that endogenous TNF soluble receptors are circulating during experimental and clinical inflammation and can protect against excessive levels of $\mathrm{TNF}^{19}$. It may be that such a protective mechanism contributed to the rapid inactivation of TNF after the bolus injections. Thus TNF could have provided a stronger signal for induction of IL-6-like activity when it was slowly infused. The fact that higher levels of IL-6-like activity were accompanied by higher thermal responses could support the hypothesis that circulating IL-6 provides the febrile signal at least for the longer second phase of the bimodal thermal response. This idea remains speculative, however, as long as no neutralizing antibodies to guinea pigs' IL-6 are available. In addition, it cannot be excluded that i.a. administered TNF exerts some direct action on the central nervous system; even a small proportion of the cytokine could have reached some areas within the central nervous system via one or more of the circumventricular organs. In this way a direct central effect of TNF per se could be responsible for the observed thermal response.

Interestingly, a baseline IL-6-like activity could be detected in each plasma even before injection or infusion of TNF and after injection or infusion of solvent. Could this measured IL-6-like activity be due to an infection or due to the chronic cannulation of the animals? For several reasons we do not believe that infection or cannulation caused the presence of IL-6 in the systemic circulation. First of all, we are aware of how infected guinea pigs change their body temperature, body weight, motor activity or drinking and eating behavior, parameters which are controlled in our experimental animals. Also the chronic cannulation can be excluded as a reason for the presence of IL-6 because in plasma of animals killed by cervical dislocation also, in which 
blood is sampled via cardiac puncture, baseline levels of IL-6 are detectable ${ }^{2.20}$. Even in healthy volunteer human subjects, IL- 6 can be detected in plasma before injection of an endotoxin ${ }^{21}$. The biological significance of the circulating baseline levels of IL-6 cannot, however, be assessed at present and remains speculative.

Our experiments highlight one more part of the socalled 'cytokine cascade', which makes it impossible to conclude whether an injected or infused cytokine is truely the natural mediator of fever. If TNF plays a role in the cytokine cascade during LPS induced fevers in guinea pigs, the contribution of this cytokine in inducing the strong release of IL-6-like activity after administration of LPS is rather small. The amount of TNF which we infused in the present study induced just $2-3 \%$ of the IL-6-like activity that can be observed during LPS fevers in guinea pigs ${ }^{6,12}$. Therefore, the intra-arterial infusion of TNF simulated only a small part of the physiological responses to LPS injections, and the significance of TNF in LPS induced fever cannot be judged until we are able to neutralize TNFlike activity during LPS fevers completely through highly specific antibodies to guinea pigs' TNF, which are not available at present.

Acknowledgments. This study was supported by the Deutsche Forschungsgemeinschaft project $183 / 4-1$ and by the National Institute of Health grant AI 27556. Excellent technical assistance of Birgit Störr is gratefully acknowledged.

1 Kluger, M. J., Physiol. Rev. 71 (1991) 93.

2 LeMay, L. G., Vander, A. J., and Kluger, M. J., Am. J. Physiol. 258 (1990) R798.
3 Long, N. C., Kunkel, S. L., Vander, A. J., and Kluger, M. J., Am. J. Physiol. 258 (1990) R332.

4 Fischer, E., Marano, M. A., Van Zee, K. J., Rock, C. S., Hawes, A. S., Thompson, W. A., DeForge, L., Kenney, J. S., Remick, D. G., Bloedow, D. C., Thompson, R. C., Lowry, S. F., and Moldawer, L. L., J, clin. Invest. 89 (1992) 1551.

5 Van Zee, K. J., DeForge, L. E., Fischer, E., Marano, M. A., Kenney, J. S., Remick, D. G., Lowry, S. F., and Moldawer, L. L., J. Immun. 146 (1991) 3478.

6 Roth, J., Conn, C. A., Kluger, M. J., and Zeisberger, E., Am. J. Physiol. 265 (1993) R653.

7 Fiers, W., FEBS Lett. 285 (1991) 1991.

8 Waage, A., Steinshamm, S., Eur. J. Haemat. 50 (1993) 243.

9 Dinarello, C. A., Cannon, J. G., Wolff, S. M., Bernheim, H. A., Beutler, B., Cerami, A., Figari, J. S., Palladino, M. A., and O'Connor, J. V., J. expl. Med. 163 (1986) 1433.

10 Michie, H. R., Spriggs, D. R., Manogue, K. R., Sherman, M. L., Revhang, A., O'Dyer, S., Arthur, K., Dinarello, C. A., Cerami, A., Wolff, S. M., Kufe, D. W., an Wilmore, D. W., Surgery 104 (1988) 280.

11 Long, N. C., Morimoto, A., Nakumori, T., and Murakami, N., Am. J. Physiol. 263 (1992) R987.

12 Roth, J., McClellan, J. L., Kluger, M. J., and Zeisberger, E., J. Physiol. Lond. 477 (1994) 177.

13 Espevic, T., and Nissen-Meyer, J., J. immun. Meth. 95 (1986) 99

14 Shrader, R. E., and Everson, G. J., Lab. Anim. Care 18 (1968) 214.

15 Aarden, L. A., DeGroot, E. R., Schaap, O. L., and Landsdorp, P. M., Eur. J. Immun. 17 (1987) 1411.

16 Blatteis, C. M., Quan, N., Xin, L., and Ungar, A. L., Brain. Res. Bull. 25 (1990) 895.

17 Ramadori, G., Van Damme, J., Reider, H., and Meyer zum Büschenfelde, K. H., Eur. J. Immun. 18 (1988) 1259.

18 Dinarello, C. A., J. Infect. Dis. I63 (1991) 1177.

19 Van Zee, K. J., Kohno, T., Fischer, E., Rock, C. S., Moldawer, L. L., Lowry, S. F., Proc. natl. Acad. Sci. USA 89 (1992) 4845.

20 LeMay, L. G., Vander, A. J., and Kluger, M. J., Physiol. Behav. 47 (1990) 957.

21 Pollmächer, T., Schreiber, W., Gudewill, S., Vedder, H., Fassbender, K., Wiedemann, K., Trachsel, L., Galanos, C., Holsboer, F., Am. J. Physiol. 264 (1993) R1007. 